\title{
RAPD and ISSR analyses of Saccharomyces cerevisiae isolates from different sources
}

\section{تحليل RAPD و Racharomyces cerevisiae J ISSR المعزولة من مصادر مختلفة}

\author{
Sawas Younus Hammadi Anmar Sael Hussein* Duha Mysire Majeed** \\ Batol Imran Dheeb Eman Noaman Ismail** \\ Department of pathological analysis ,College of Applied Sciences, University of Samarra. \\ College of medicine, Faluja University. * \\ Biotechnology Research Center, Al-Nahrain University. **

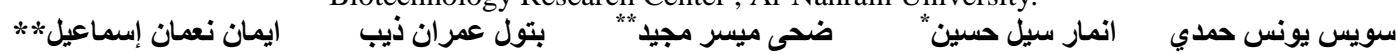 \\ قسم التحليلات المرضية/ كلية العلوم الصرفة/ جامعة سامر اء

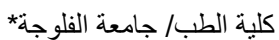 \\ ** مركز بحوث التقنيات الاحيائية / جامعة النهرين
}

Corresponding author e-mail address: batoolomram@yahoo.com

\begin{abstract}
The purpose of this study was to isolate the Saccharomyces cerevisiae present on different fruits and performing RAPD and ISSR analyses to know the genetic interrelationship between different $S$. cerevisiae isolates. Some fruits namely apple, plum, dates, and peach were used as natural sources for $S$. cerevisiae isolation. The isolated $S$. cerevisiae was designated as SUC1, SUC2, SUC3, SUC4, SUC5 respectively. Amplicon fingerprints for the isolated species were obtained by RAPD assay using six different primers and ISSR assay using six different primers. RAPD assay showed the lowest genetic distance $(0.1559)$ between SUC2 and SUC3 isolates whereas ISSR assay showed the lowest genetic distance (0.06899) between SUC4 and SUC5 isolates. Both genetic markers showed the highest genetic distance for SUC1 when compared to the other isolates.
\end{abstract}

Key words: RAPD and ISSR assay, Saccharomyces cerevisiae, Bread yeast, Apple, Plum, Dates, Peach.

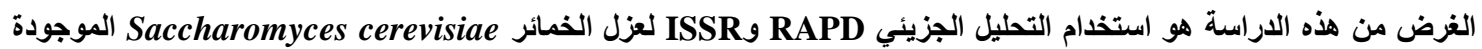

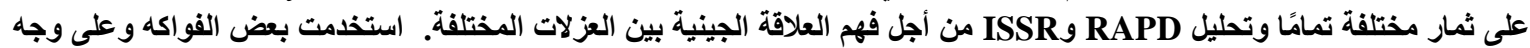

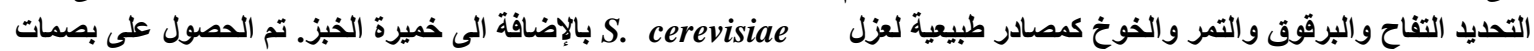

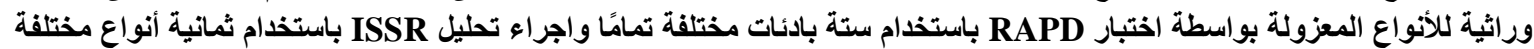

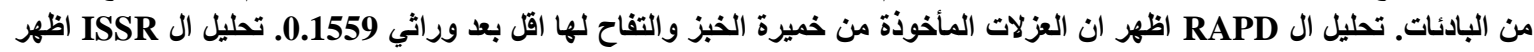

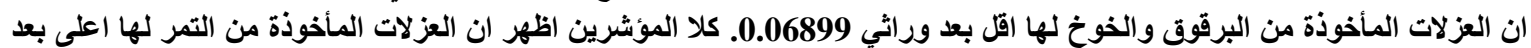
وراثي مع العزلات الأخرى.

الكلمات المفتاحية: تحليل ISSR و Saccharomyces cerevisiae , RAPD , خميرة الخبز، تفاح، برقوق، تمر، خوخ.

\section{Introduction}

Saccharomyces cerevisiae is a unicellular eukaryotic fungus, very common in the environment and is mostly saprophytic because their cells do not contain chlorophyll. [1]. S. cerevisiae comes in the forefront of microbiological groups used in the industrial and production areas as well as most consumed by humans where they are safe and produce non-toxic materials [2], It has been made as a model organism of study on both research and industrial importance [3]. Fermenting wild yeast species are being isolated from the natural sources for over decades and is being used in various fermentation processes. S. cerevisiae feeding is of the heterotrophic type so it has been isolated from a variety of natural sources like leaves, flowers, fruits etc. [4, 5]. Being a sugar-loving microorganism, it is usually isolated from sugar-rich materials. Fruits contain high sugar concentration so yeast species are naturally present on them and can be easily isolated from them. Distinct wild yeast species are supposed to be present and associated with different fruits in natural environments [6]. Traditional methods like morphological, physiological and biochemical studies used for taxonomic identification of yeast isolates [7, 8]. But being laborious and timeconsuming techniques, they are not appropriate for routine identification [9]. Molecular biology-based methods have been developed and can be applied to the field of yeast taxonomy in routine identification works [10]. One of the diagnostic methods for S. cerevisiae is Polymerase Chain Reaction (PCR), which can amplify some specific fragment of DNA into millions of copies [11, 12]. In recent years, different molecular typing techniques have been applied to study the genetic diversity of $S$. cerevisiae and the possible 
occurrence of similarity and difference between them, Random Amplified Polymorphic DNA (RAPD) analysis can be performed as a method for study genetic diversity with a large number of different strains of microorganisms. It is inexpensive and requires less amount of DNA [13]. Moreover, RAPD analysis is technically being commonly used as an indicator for determining the genetic diversity, while Inter-simple sequence repeat technique ISSR analysis based on variation found in the regions between microsatellites it has been used in genetic fingerprinting gene tagging and detection of clonal variation [14]. This technique which involved amplification of DNA segment present in between two identical microsatellite repeat regions by addition the oriental in opposite direction with suitable distances ISSR method has been reported produce more complex markers patterns than the RAPD markers in addition, ISSR method are more reproducible than RAPD method because ISSR primers designed to anneal temperature to a microsatellite sequences are long than RAPD primers, allowing higher annealing temperature to be used. It also because of multilocus fingerprinting profile obtained ISSR has been found to be an efficient, low cost, simple operation, high stability and abundance of $[15,16]$. The aim of the study was to determine the effect of the nutritional components on the genetic components of the yeast as well as to detect the unique bands and polymorphism between isolates and to compare between RAPD and ISSR markers for genetic diversity between different $S$. cerevisiae isolates.

\section{Materials and Methods}

Isolation of $S$. cerevisiae

A total of five $S$. cerevisiae and fruit source isolates as shown in (Table-1)

Table (1): Saccharomyces cerevisiae isolates examined during this study

\begin{tabular}{lcc}
\hline \multicolumn{1}{c}{ S. cerevisiae isolates } & \multicolumn{2}{c}{ S. cerevisiae fruit source } \\
& Common name & Scientific name \\
\hline SCU1 & Dates & Phoenix dactylifera \\
SCU2 & Bread yeast & Saccharomyces cerevisiae \\
SCU3 & Apple & Malus pumila \\
SCU4 & Plum & Prunus cultivar \\
SCU5 & Peach & Prunus persica \\
\hline
\end{tabular}

Fruit samples were obtained from local markets, $100 \mathrm{~g}$ of each fruit sample was taken in a sterile mortar and crushed to a fine paste by mixing with sterile water. Then, the mixture was kept for overnight at room temperature so that natural wild yeast present on fruit samples might grow and develop to enrichment culture. As for bread yeast, $0.1 \mathrm{~g}$ of dry yeast was suspended in tubes containing $10 \mathrm{~mL}$. of sterile distilled water and incubated for $30 \mathrm{~min}$ at $30^{\circ} \mathrm{C}$ and the stuck as with Vortex. Streaked an equal amount of the liquid portion of each sample and planted on the Yeast Extract Peptone Dextrose (YEPD) medium (This medium is prepared by dissolving $20 \mathrm{~g}$ glucose, $20 \mathrm{~g}$ peptone and $10 \mathrm{~g}$ yeast extract in 1 litre of distilled water and adding $20 \mathrm{~g}$ of agar with $\mathrm{pH} 5$ and then sterilized by autoclave. This medium is used to stimulate, diagnose and develop S. cerevisiae isolates [17]. Streaked plates were incubated at $30 \pm{ }^{\circ} \mathrm{C}$ for $48 \mathrm{~h}$. After the emergence of growth taking part in a single colony was streaked onto the anew YPED plate and incubated at $30 \pm{ }^{\circ} \mathrm{C}$ for $48 \mathrm{~h}$. This process was repeated until a pure culture was obtained which was confirmed by examining the cells under a light microscope.

\section{Genomic DNA extraction}

The DNA was extracted by small-scale methodology industrial kit (Bioneer-Korea). DNA purity was measured counting on optical density by spectrophotometer. DNA quality was determined by agarose gel electrophoresis stained $0.5 \mathrm{mg} / \mathrm{ml}$ with ethidium bromide and visualized under Ultra Violet light [18].

\section{Molecular Analysis}




\section{RAPD assay}

Six of RAPD primers were utilized in this study, the primers were synthesized by (Bioneer-Korea) in lyophilized type and dissolved in sterile water to obtain a final concentration of (10pmol/ml), [19, 20, 21]. The primers and their sequences are listed in Table(2).

Table (2): The names and sequences of the primers used in this study

\begin{tabular}{ccc}
\hline No. & Primers name & Sequences $\left({ }^{\prime} \mathbf{5}-{ }^{\prime} \mathbf{3}\right)$ \\
\hline $\mathbf{1}$ & OPI -06 & AAGGCGGCAG \\
$\mathbf{3}$ & OPE-16 & GGTGACTGTT \\
$\mathbf{4}$ & OPN-07 & GAGCCCCGAG \\
$\mathbf{5}$ & OPQ-17 & GAAGCCCTTG \\
$\mathbf{6}$ & OPD-20 & ACCCGGTCAC \\
\hline
\end{tabular}

Amplification of genomic DNA was performed with the master amplification reaction as illustrated in Table (3).

Table (3): Master reaction of RAPD

\begin{tabular}{ccc}
\hline Materials & Volume for $\mathbf{1}$ tube $\boldsymbol{\mu l}$ & Final concentration \\
\hline PCR premix & 5 & $1 \mathrm{x}$ \\
Deionised D.W & 11 & - \\
Primer (10 pmol/ $\mu \mathrm{l})$ & 2 & $10 \mathrm{pmol} / \mu \mathrm{l}$ \\
DNA template & 2 & $100 \mathrm{ng}$ \\
\hline
\end{tabular}

RAPD - PCR premix (final reaction volume $=20 \mu \mathrm{I}$ ). No. of cycles $=40$ cycles between initial denaturation and final extension, was shown in Table (4).

Table (4): The RAPD assay program

\begin{tabular}{cccc}
\hline Steps & Temperature $\left({ }^{\circ} \mathbf{C}\right)$ & Time $(\mathbf{m i n})$ & Number of cycles \\
\hline Initial denaturation & 94 & 5 & 1 \\
Denaturation & 94 & 1 & $35-40$ \\
Annealing & 36 & 1 & \\
Extension & 72 & 2 & 1 \\
Final extension & 72 & 10 & \\
\hline
\end{tabular}


Each PCR amplification reaction was continual double to confirm dependability the products analyzed by electrophoresis in $1-1.5 \%$ agarose with $0.5 \mu 1$ stained ethidium bromide at $5 \mathrm{v} / \mathrm{cm}$ for $2 \mathrm{~h}$.

\section{ISSR assay}

Six of ISSR primers were used they were provided by (Bioneer - Korea) in lyophilized type and dissolved in sterile distilled water to obtain a final concentration of $(10 \mathrm{pmol} / \mathrm{ml})$ [19, 22]. as recommended by the supplier. The primers that tested during this study are listed in Table (5).

Table (5): The names and sequences of the primers used in this study

\begin{tabular}{ccc}
\hline No & Primers Name & Sequence ('5-'3) \\
\hline $\mathbf{1}$ & ISSR $_{2}$ & GACAGACAGACAGACAGACAA \\
$\mathbf{2}$ & $\mathrm{ISSR}_{6}$ & AGAGAGAGAGAGAGAGAGAGC \\
$\mathbf{4}$ & $\mathrm{ISSR}_{7}$ & AGAGAGAGAGAGAGAGAGAGT \\
$\mathbf{5}$ & $\mathrm{ISSR}_{8}$ & CTCTCTCTCTCTCTCTCTCTA \\
$\mathbf{6}$ & $\mathrm{ISSR}_{9}$ & \\
& $\mathrm{ISSR}_{10}$ & CTCTCTCTCTCTCTCTCTCTG \\
\end{tabular}

Following master amplification reaction as represented in Table (6).

Table (6): Master reaction of ISSR

\begin{tabular}{ccc}
\hline Materials & Volume for $\mathbf{1}$ reaction $(\boldsymbol{\mu l})$ & Final concentration \\
\hline PCR premix & 5 & $1 \mathrm{x}$ \\
Deionised D.W & 17 & $10 \mathrm{pmol} / \mu \mathrm{l}$ \\
Primer $(\mathbf{1 0} \mathbf{~ p m o l} / \boldsymbol{\mu l})$ & 2 & $100 \mathrm{ng}$ \\
DNA template & 1 & \\
\hline
\end{tabular}

The final concentration was performed in a volume of 20-25 $\mu$. PCR program for ISSR assay exploitation the subsequent program which showed in Table (7).

Table (7): The ISSR assay program

\begin{tabular}{cccc}
\hline Steps & Temperature $\left({ }^{\circ} \mathbf{C}\right)$ & Time $(\mathbf{m i n})$ & Number of cycles \\
\hline Initial denaturation & 94 & 5 & 1 \\
Denaturation & 94 & 1 & $35-40$ \\
Annealing & 50 & 1 & \\
Extension & 72 & 1 & 1 \\
Final extension & 72 & 10 &
\end{tabular}

Each PCR amplification reaction was repeated twice to ensure reproducibility the products analyzed by electrophoresis in $1-1.5 \%$ agarose with stained ethidium bromide $0.5 \mu \mathrm{l}$ at $5 \mathrm{v} / \mathrm{cm}$ for $2 \mathrm{~h}$. 


\section{Data analysis}

\section{Estimation of molecular weight}

Computer software Photo-Capture M.W. program was used to determine molecular weight based on comparing the RAPD-PCR and ISSR-PCR products with molecular weight marker bands from (Bioneer Korea) (which consist of 13 bands from 100 to 2000 bp.)

Estimation of polymorphism, efficiency and discriminatory power .

Data generated for molecular weight RAPD and ISSR markers result bands were scored for each band on the molecular size (1 for a present, 0 for absence) the commercial software [23, 20, 24, 25]. Only major bands consistently amplified were scored. Polymorphism of each primer was calculated based on the following formula:

$$
\text { Polymorphism } \%=(\mathrm{Np} / \mathrm{Nt}) \times 100
$$

Where $\mathrm{Np}=$ the number of polymorphic bands of random primer, $\mathrm{Nt}=$ the total number of bands of the same primer. Efficiency and discriminatory power of each primer calculated according to the formula below: - Efficiency =number of the polymorphic bands to each primer / total number of bands to the same primer.

- Discriminating power= number of the polymorphic band to each primer / total number of polymorphic bands to all primer $\times 100 \%$.

Primer efficiency ranged between (0-1). Discrimination power of each primer.

\section{Results and Discussion}

5 yeast species were isolated, purified and morphological as well as genetic diversity analysis using RAPD and ISSR methods were successfully carried out. Yeast specific defined media used was able to inhibit the growth of bacterial population in all the cultures. Some fungal contamination was seen after 3 days of incubation of primary cultures. Pure cultures were easily made by taking part of the colonies by a loop and streaked on the medium and repeated more than once that the colonies were obtained individually and pure yeast culture became dominant (that growth after 7 days). Morphological data based on different parameters of colony characteristics are tabulated in Table (8).

Table (8): colony morphological data of different $S$. cerevisiae isolates

\begin{tabular}{llllll}
\hline S. cerevisiae isolates & Color & Shape & Surface & Elevation & Edge \\
\hline SCU1 & Cream & Oval & Glistening & Flat & Curled \\
SCU2 & White & Circular & Smooth & Raised & Curled \\
SCU3 & White & Circular & Wrinkled & Bulged & Curled \\
SCU4 & White & Circular & Smooth & Convex & Curled \\
SCU5 & White & Circular & Wrinkled & Convex & Curled \\
& & & & & \\
\hline
\end{tabular}

The five isolates, in general, showed common morphological characteristics. Common characteristics were found between SCU3 with SCU5 compared to the other species. A similarity was also observed between the SCU4 and SCU5. While SCU1 showed more variation than other isolates. Dates contain $75 \%$ sugars compared to other isolates, the presence of high concentration of sugar in the food medium leads to the formation of large amounts of alcohol even under the conditions of air, as the yeast is negatively affected by alcohol produced by the food medium [26, 27]. These results are similar to a study [28, 29, 30].

\section{RAPD-PCR analysis}




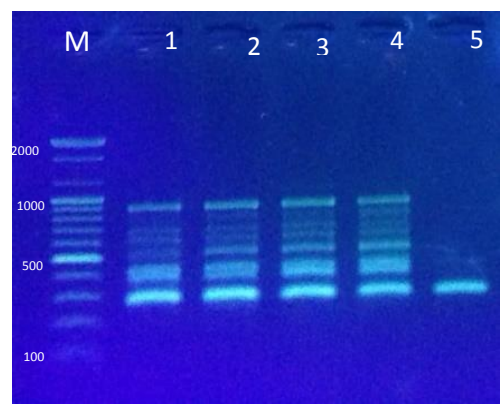

OPI -06

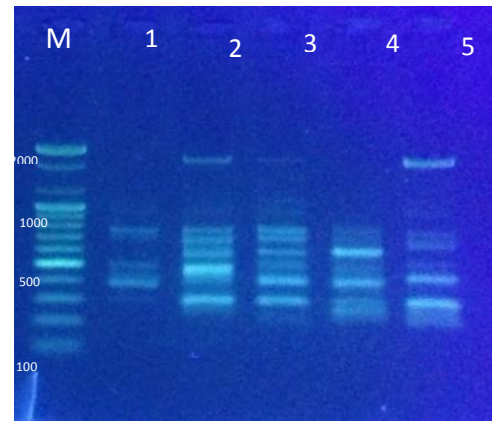

OPQ-17

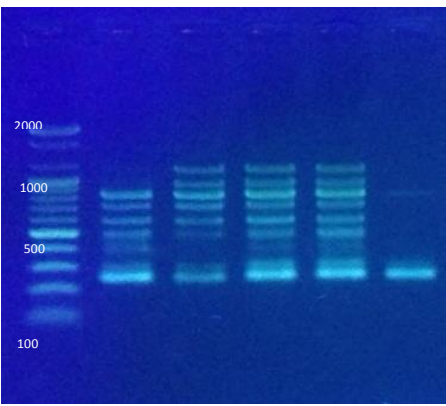

OPE-16

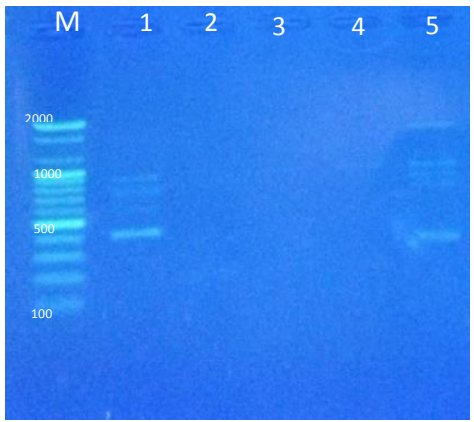

OPD-20

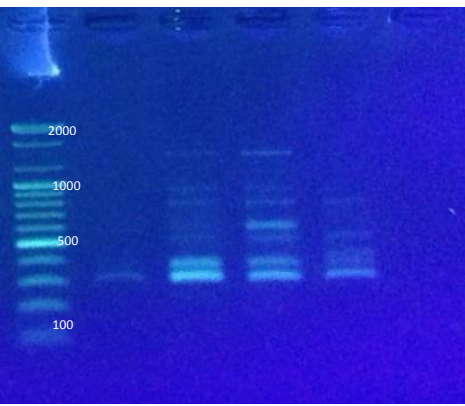

OPN-07

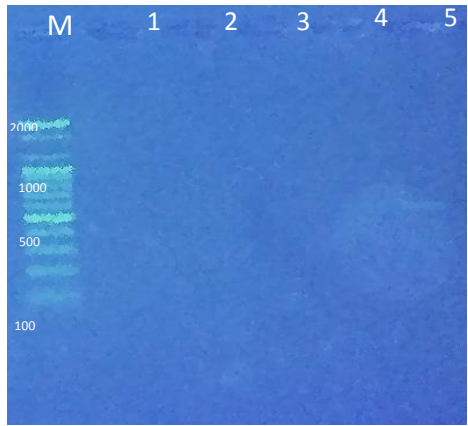

OPL-05

Figure (1): PCR amplifications RAPD primer on 1-1.5\% agarose gel electrophoresis with ethidium bromide, $M=1000$ bp.

Lines= S. cerevisiae isolates (SCU1, SCU2, SCU3, SCU4, SCU5), (1X TBE, 5v/cm, $2 \mathrm{~h}, 0.5 \mathrm{mg} / \mathrm{ml}$ ethidium bromide)

Based on RAPD assay the data developed from the PCR analysis demonstrated that some primers generate several bands, while other generates only a few bands. A total of six RAPD primers were used for study the genetic differences between five $S$. cerevisiae isolates, amplified 111 bands, 101 bands were polymorphic, with average of (1-26) polymorphic bands, that OPD-20 produce 1 polymorphic band only, were OPN-17 can be produce 26 polymorphic bands with average range size (300-1700) bp. Some isolates could be distinguished from all other isolates with a selection of these primers, for instance, OPI-06 primers can produce lower discrimination power 80.7 bands only, while OPL-05 gave 4 unique bands patterns Table (5). 
Table (9): Distinct characteristics of RAPD primers included in the study: primers name, total number of bands, number of polymorphic bands, number of unique bands, percentage of polymorphism, primer efficiency and discrimination value.

\begin{tabular}{|c|c|c|c|c|c|c|c|}
\hline No. & $\begin{array}{l}\text { Name of } \\
\text { primers }\end{array}$ & $\begin{array}{l}\text { Total number of } \\
\text { main bands }\end{array}$ & $\begin{array}{c}\text { Number unique } \\
\text { bands }\end{array}$ & $\begin{array}{c}\text { Number } \\
\text { polymorphic } \\
\text { bands }\end{array}$ & Polymorphism \% & $\begin{array}{c}\text { Primer } \\
\text { efficiency }\end{array}$ & $\begin{array}{c}\text { Discrimination } \\
\text { power }\end{array}$ \\
\hline 1 & $\mathrm{P} 1$ & 26 & 1 & 21 & 3.84 & 0.8 & 80.7 \\
\hline 2 & $\mathrm{P} 2$ & 19 & 2 & 19 & 5.26 & 1 & 100 \\
\hline 3 & P3 & 29 & 1 & 24 & 3.44 & 0.82 & 82.7 \\
\hline 4 & P4 & 26 & 0 & 26 & 3.84 & 1 & 100 \\
\hline 5 & P5 & 1 & 1 & 1 & 100 & 1 & 100 \\
\hline 6 & P6 & 10 & 4 & 10 & 10 & 1 & 100 \\
\hline
\end{tabular}

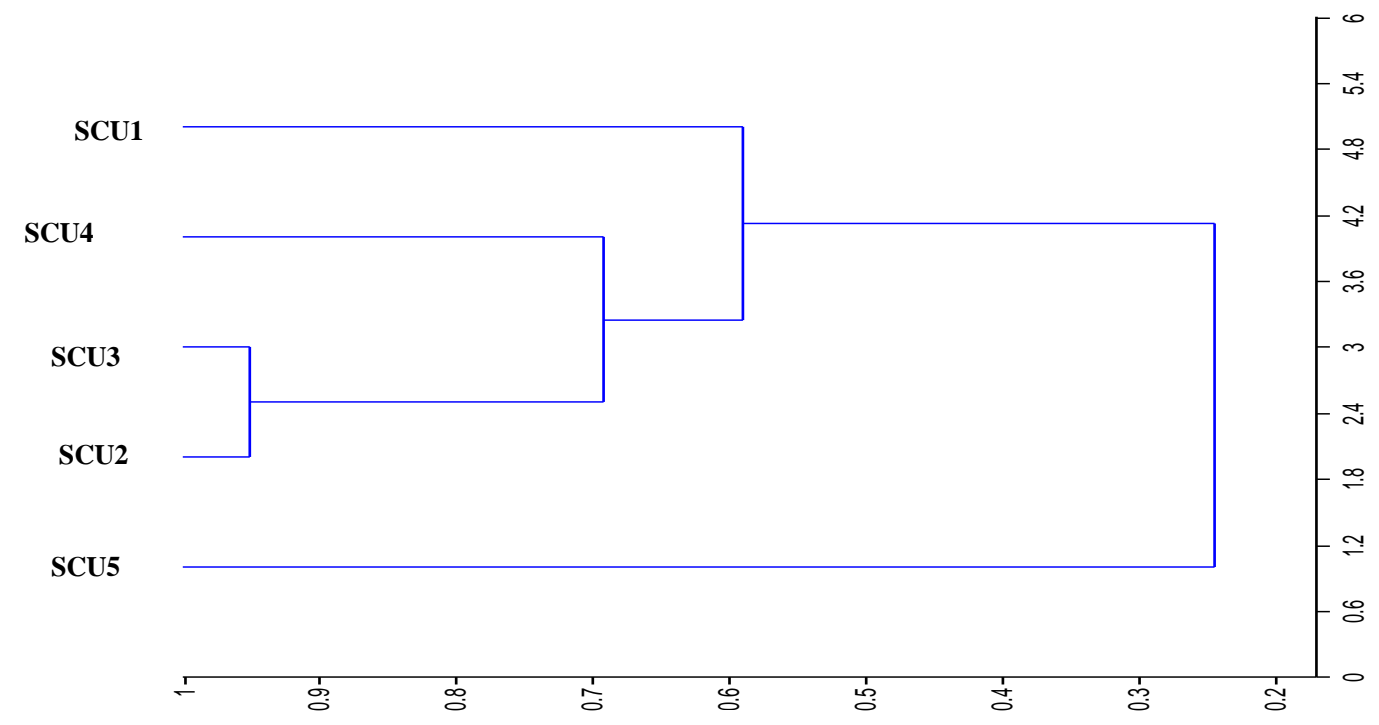

Figure (2): Dendrogram illustrated genetic fingerprint and relationship between $S$. cerevisiae isolates developed from RAPD data.

Table (10): Values of genetic distance among S. cerevisiae Isolates calculated according to Nei and Lei, 1979).

\begin{tabular}{cccccc}
\hline No. & 1 & 2 & 3 & 4 & 5 \\
\hline 1 & 0.0000 & & & & \\
2 & 0.89781 & 0.0000 & & & \\
3 & 0.78148 & 0.1559 & 0.0000 & & \\
4 & 0.75588 & 0.8049 & 0.69503 & 0.0000 & 0.0000 \\
5 & 1.3497 & 1.1466 & 0.98821 & 1.3105 & \\
\hline
\end{tabular}

The dendrogram clearly showing the sufficient distance to form apart clusters. Cluster analysis illustrated a genetic relationship among five of $\mathbf{S}$. cerevisiae isolates showing two major clusters (figure-2), the first cluster contained SCU2 and SCU3 isolates with low genetic distance 0.1559. These were introduced 
from bread yeast and apple sources respectively. This indicates the genetic similarity between the isolated species of the yeast and the apple and this was not apparent in the form of the colonies where the colony was taken from the yeast of bread more like the colony taken from this plum illustrates the accuracy of genetic analysis compared to the analysis of the phenomenon. Isolate SCU1 and SCU4 formed a separated line, while the second group contained SCU5. Table (8) illustrates the highest genetic dimension between the sample taken from dates and the sample taken from peach.

\section{ISSR-PCR analysis}

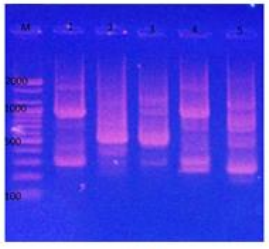

$\mathrm{ISSR}_{2}$

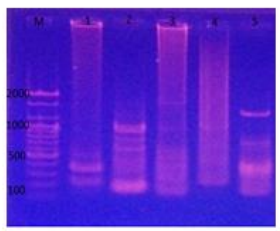

$\mathrm{ISSR}_{8}$

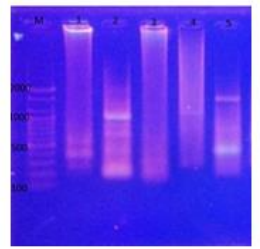

ISSR $_{6}$

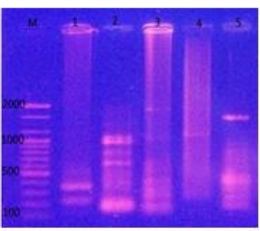

ISSR9

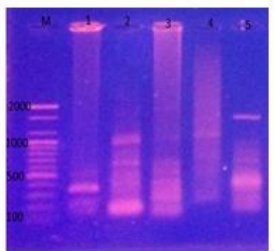

$\mathrm{ISSR}_{\text {? }}$

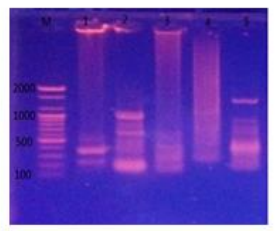

ISSR $_{10}$

Figure (3): PCR produced ISSR primer on 1-1.5\% agarose gel electrophoresis with ethidium bromide, M=1000 bp. , Lines= S. cerevisiae isolates (SCU1, SCU2, SCU3, SCU4, SCU5), (1X TBE, 5v/cm, 3h, 0.5mg/ml ethidium bromide).

In this study, ISSR-PCR technique was used to reveal the genetic diversity among different studied $S$. cerevisiae isolates in order to search the genetic diversity between $S$. cerevisiae isolates and study the differences that come from the environment. A total of 145 using full bands were scored from the amplified products with the eight Inter-Simple Sequence Repeat (ISSR), 100 bands were polymorphic, with the average of 4 polymorphic bands ISSR4, and ISSR3, ISSR7 produce 19 polymorphic bands with average range size (250-1600) bp. (figure-3). ISSR8 primers can produce high unique bands can produce 5 unique bands, Table(7).

Table (11): Distinct characteristics of ISSR primers including in the study: primers name, total number of bands, number of polymorphic bands, number of unique bands, percentage of polymorphism, primer efficiency and discrimination value.

\begin{tabular}{|ccccccccc}
\hline No. & $\begin{array}{c}\text { Name of } \\
\text { primers }\end{array}$ & $\begin{array}{c}\text { Total number of } \\
\text { main bands }\end{array}$ & $\begin{array}{c}\text { Number of unique } \\
\text { bands }\end{array}$ & $\begin{array}{c}\text { Number of } \\
\text { polymorphic } \\
\text { bands }\end{array}$ & $\begin{array}{c}\text { Polymorphism \% } \\
\text { efficiency }\end{array}$ & $\begin{array}{c}\text { Discrimination } \\
\text { power }\end{array}$ \\
\hline 1 & P1 & 15 & 2 & 10 & 6.66 & 0.66 & 66.6 \\
2 & P2 & 16 & 0 & 6 & 6.25 & 5.37 & 1 & \\
3 & P3 & 19 & 0 & 19 & 5.26 & 11.1 & 0.44 & 44.4 \\
4 & P4 & 9 & 0 & 4 & 5.26 & 0.47 & 47.3 \\
5 & P5 & 19 & 1 & 9 & 4.54 & 0.77 & 77.2 \\
6 & P6 & 22 & 1 & 17 & 4.16 & 0.79 & 79 \\
7 & P7 & 24 & 3 & 19 & 4.76 & 0.76 & 76.1 \\
\hline
\end{tabular}

From the genetic distance, the ratio of genetic similarity among the five $S$. cerevisiae isolates from 0.65791 to 0.06899 (table-9). The highest genetic distance 0.65791 between isolate SCU1, SCU3 and SCU4 respectively. While 0.41926 genetic distance between isolates SCU4 and SCU5 with isolate SCU2, but the 
lowest level of genetic distance 0.06899 appeared between isolate SCU4 and SCU5 which Indicates the genetic similarity because they belong to the same genus Prunus.

Table (12): Values of genetic distance among S. cerevisiae Isolates calculated according to Nei and Lei, 1979).

\begin{tabular}{cccccc}
\hline No & 1 & 2 & 3 & 4 & 5 \\
\hline 1 & 0.00000 & & & & \\
2 & 0.51285 & 0.00000 & & & \\
3 & 0.65791 & 0.37274 & 0.00000 & & \\
4 & 0.65791 & 0.41926 & 0.51083 & 0.00000 & \\
5 & 0.58380 & 0.41926 & 0.40547 & 0.06899 & 0.00000 \\
\hline
\end{tabular}

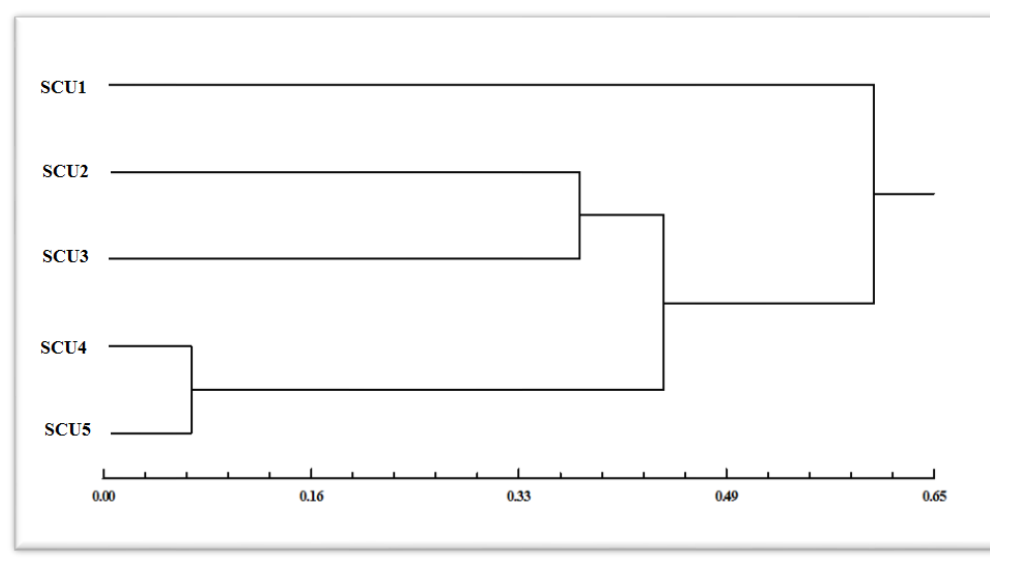

Figure (4): Dendrogramillustrated genetic fingerprint and relationship among

S. cerevisiae isolates developed from ISSR data.

During dendrogram were constructed based on Nei and Lei (1979). Genetic distance using UPGMA cluster analysis and depicted genetic relationship $\quad{ }_{r}$ re cerevisiae isolates showing two major clusters, the first cluster contained two main group, the first group contained SCU2 and SCU3 while the second group contained SCU4 and SCU5 formed another sub-cluster with low genetic distance 0.06899 and second cluster contained isolate SCU1. The characteristics of the individual genes are the result of the genetic material inherited by the individual of the parents in addition to the impact of the environment. In this study, the effect of the environment (dietary medium) on which the yeast was grown is evident through the results of the analysis of the RAPD using a random sequence of primers and ISSR using a sequence of specialized primers the total number of bands resulting from the RAPD analysis was 111 bands. The number of a polymorphic band was 101 bands and 9 unique bands as for the ISSR markers, it is giving 145 bands. The polymorphic band was 100 bands and the number of unique bands was 12 bands. Meaning that yeast isolates contained sequences own specialized indices rather than random indicators appeared in both markers RAPD and ISSR the extent of convergence between isolates SCU2 and SCU3, as well as near the isolates SCU4 and SCU5, as well as appeared in both markers in addition to phenotypic analysis that the isolate SCU1 is furthest from the other samples. Presence of yeast species on fruits can also be dependent on the geographical factors as well as the place from where the fruits are obtained [28] and their further postharvesting treatment. In this study, we did not have information about the nature of the treatment suffered by fruit in their environment before they are used in the study. It may have been exposed to some chemical transactions that may have led to obtain mutations or delete or add to the rules of nitrogenous but it is clearly proved in the dendrogram that yeast isolated from different sources are very much different from each other, being, may be of different species or of different strains. 


\section{Conclusion}

Presence of genetic diversity using RAPD and ISSR analysis as well as different observed colony morphological characteristics in the yeast strains from different fruit sources, it purposes a methodology for easy and quick isolation of yeast strains for both research and industrial analysis.

\section{References}

1. Kreger-van Rij, N. J. W. (1984). The Yeasts: A Taxonomic Study. Elsevier Science Publishers BV, Amsterdam, 3rd ed., pp. 893-905.

2. Camacho-Ruiz, L., Perez-Guerra, N. and Perez-Roses, R. (2003). Factors effecting the growth of Saccharomyces cerevisiae in batchculture and solid-state fermentation. Environ. Agri. and Food Chem. 2(5):1579-4377.

3. Legras, J. L., Merdinoglu, D., Cornuet, J.M. and Karst, F. (2007). Bread, beer and wine: Saccharomyces cerevisiae diversity reflects human history. Mol. Ecol. 16 (10): 2091-2102.

4. Li, H.; Veenendaal, E., Shukor, N. A., Cobbinah, J. R. and Leifert, C. (2008). Yeast populations on the tropical timber tree species Milicia excels. Lett. Appl. Microbiol. 21(5): $322-326$.

5. Al-Tekreeti, A. R., Al-Halbosiy, M. M. F., Dheeb, B. I., Hashim, A. J. and Al-Zuhairi, A. F. H. (2017). Molecular identification of clinical Candida isolates by simple and randomly amplified polymorphic DNA-PCR. Arab J Sci Eng. DOI 10.1007/s13369-017-2762-1.

6. Spencer, J. F. T. and Spencer, D. M. (1997). Yeasts in Natural and Artificial Habitats. SpringerVerlag, Berlin- Heidelberg.p.381.

7. Kurtzman, C. P., Fell, J. W., Rosa, C. A. and Peter, G. (2006). Yeast systematics and phylogeny implications of molecular identification methods for studies in ecology. The Yeast Handbook. Germany: Springer-Verlag, Berlin-Herdelberg, pp.11-30.

8. Dheeb, B. I., Al-Halbosiy, M. M. F., Al lihabi, R. K. and Khashman, B. M. (2016). The effects of Rubusidaeus extract on normal human lymphocytes and cancer cell line. BMC Genomics 17(Suppl 6): p. 19

9. Couto, M. M. B., Vossen, J. M. B. M., Hofstra, H. and Huis Veld, J. H. J. (1994). RAPD analysis: a rapid technique for differentiation of spoilage yeasts. Intern. J. Food Microbiol. 24(1 2): 249-260.

10. Loureiro, V. and Malfeito-Ferreira, M. (2003). Spoilage yeasts in the wine industry. Int. J. Food Microbiol. 86 (1-2): 23-50.

11. McPherson, M. J. and Møller, S. G. (2001). PCR the basic background to bench. Cornwell Press, Trowbridge, UK.

12. Nouri, M. A., Al-Halbosiy, M. M. F., Dheeb, B. I. and Hashim, A. J. (2015). Cytotoxicity and genotoxicity of gliotoxin on human lymphocytes in vitro.Journal of $K S U$-Science. 27, 193197.

13. Panepinto, J. C., Pardo, J., Urban, C., and Galvez, E. M. (2010). The mitochondrial protein Bak is pivotal for gliotoxin-induced apoptosis and a critical host factor of Aspergillus fumigatus virulence in mice. J. Cell Biol. 174:509-519.

14. Bornet, B. and Branchard, M. (2001). Nonanchored Inter Simple Sequence Repeat (ISSR) markers: reproducible and specific tools for genome fingerprinting. Plant Mol. Biol. Rep.19:209215.

15. Zietkiewics, E., Rafalski, A. and Labuda, D. (1994). Genome fingerprinting by Simple Sequence Repeat (SSR) anchored polymerase chain reaction amplification. Genomics. 20: 176-183.

16. Hussain, A. F., Sulaiman, G. M., Dheeb, B. I., Hashim, A. J. and Seddiq, S. H. (2017). Improving conditions for gliotoxin production by local isolates of Aspergillus fumigatus. Journal of biotechnology research center. 11(2):14-24.

17. Ono, B., Ishi, N., Fujino, S., and Aoyama, I. (1991). Role of hydrosulfide ions (HS-) methylmercury resistance in Saccharomyces cerevisiae. Appl. Environ. Microbiol. 57(11):3183 $-3186$.

18. Sambrook, J. and Russell, D. W. (2001). Molecular Cloning. In: "A Laboratory Manual". Cold Spring Harbor Laboratory Press, Cold Spring Harbor, N. Y. 
19. Hatti, A. D., Taware, S. D., Taware, A. S., Pangrikar, P. P., Chavan, A. M. and Mukadam, D. S. (2010). Genetic diversity of toxigenic and non-toxigenic.

20. Dheeb, B. I. (2014). Immunohistochemical study of Tumor Necrosis Factoralpha(TNF- $\alpha$ ) expression in lung, liver, and spleen during aspergillosis infection. BMC genomics. 15 (2), 71.

21. Rassin, N. K., Nemat J. A, Dheeb, B. I. (2015). Molecular Identification of Aspergillus fumigatus Using ISSR and RAPD Markers. Iraqi Journal of Science. 56 (4A), 2788-2797.

22. Dheeb, B. I., Al-Mashhadani, I. I., Ismail, E. N., Majeed, S. M., and Majeed, D. M. (2014). A Study of the Expression of Aflatoxin B1 Regulatory Gene in Clinical and Environmental Aspergillusflavus using Real-time PCR. I J S: B A R, 17 (1), 417-427.

23. Bibi, S., Dahot, M. U., Khan, I. A., Khatri, A. and Naqvi, A. (2011). Study of genetic diversity in wheat (Triticum aestivum L.) using random amplified polymorphic DNA (RAPD) markers. Pakistan J. Botany 41, 1023-1027.

24. Ibrahim, I. M., Iftikhar, M., Ali, I. M., Dheeb, B. I., Abbas, Q. A., Ramizy, A., Eisa, M. H. and Aljameel, A. I. (2017). Antifungal activity of wide band gap Thioglycolic acid capped ZnS:Mn semiconductor nanoparticles against some pathogenic fungi Materials Science and Engineering C 73:665-669

25. Bander, K. I., Mohammed, S. H., Thalij, K. M. and Dheeb, B.I. (2015). Survey Study of the Allergic Fungi in Kirkuk Area and Use Molecular Detection for Identification. I J S: B A R. 19(1):383-397.

26. AL-Eqabi, H. F. E. (2009). Extraction of mannan from yeastSaccharomyces cerevisiae and study of its agglutination activity. Thesis Submitted to the college of science-University of Baghdad.Iraq.

27. Dheeb, B. I., Al-Mudallal, N. H., Salman, Z. A. and Ali, M. (2015). The Inhibitory Effects of Human, Camel and Cow's Milk against Some Pathogenic Fungi in Iraq. Jordan Journal of Biological Sciences. 8(2) 89 - 93.

28. Lathare, P. K., Sharma, A. and Thakur, I. (2010). Isolation and random amplified polymorphic DNA(RAPD) analysis of wild yeast species from 17 different fruits. J. of Yeast and Fungal Research. 1(8):146 - 151.

29. El-Hilali, F., El-Hilali, H., Dheeb, B. I., Traore, B. M., Messouak, M., Mazouz, H., Moumni, M., Belgacem, F. B. M. and El-Mowafy, A. M. (2016). Blood Transfusion Utility During Cardiopulmonary Bypass and Correlation with Key-Biochemical Laboratory Findings: A New Approach to Identify Preventive and Risk Factors (1-Year Practice at University Hospital Hassan-II of Fez).Biochem Anal Biochem. 5:3 DOI: 10.4172/2161-1009.1000290

30. Abdulbaqi, N. J. and Dheeb, B. I. and Irshad, R. (2018). Expression of Biotransformation and Antioxidant Genes in the Liver of Albino Mice after Exposure to Aflatoxin B1 and an Antioxidant Sourced from Turmeric (Curcuma longa). Jordan Journal of Biological Sciences. 11(2) $89-93$.

31. Nei, M. and Li, W. H. (1979). Mathematical model for studying genetic variation in terms of restriction endonucleases. Proc. Natl. Acad.Sci, USA .76: 5269-5273. 